\title{
LAS BUENAS MUJERES DE FINALES DE LA EDAD MEDIA. RECONSTRUCCIÓN DE UN MODELO A PARTIR DE LAS FUENTES VASCAS ${ }^{1}$
}

\author{
Janire Castrillo ${ }^{2}$
}

\begin{abstract}
Las buenas mujeres de finales de la Edad media. Reconstrucción de un modelo a partir de las fuentes vascas.

Resumen: Este trabajo analiza las características que conformaban el arquetipo de buenas mujeres en las postrimerías de la Edad Media. Su reconstrucción se realiza a través de datos extraídos de fuentes vascas de diversa tipología, que van desde fueros y ordenanzas municipales, hasta documentos notariales y procesos judiciales, junto a extractos de algunas crónicas. A partir del estudio de dicho conjunto documental, se esboza una imagen de las principales cualidades que se atribuían a las mujeres virtuosas en la época, fundamentalmente: la castidad, la asistencia parental y vecinal, la devoción y la caridad, y el recato y el comedimiento.
\end{abstract}

Palabras clave: Mujeres, Edad Media, modelo de buena mujer, arquetipo, país vasco.

\section{The Good Women of the Late Middle Ages. Reconstruction of a Model through Basque} Sources.

Abstract: This study analyzes the characteristics that shaped the archetype of good women at the end of the Middle Ages. The reconstruction is carried out through data extracted from Basque sources of different types, ranging from fueros and municipal ordinances, to wills and other notarial documents, judicial proceedings and references extracted from some chronicles. The study of this collection of documents allows us to draw out the image of virtuous women at that time, as well as the qualities attributed to them: chastity, parental and neighbourhood assistance, devotion and charity, and modesty and moderation.

Key words: Women, Middle Ages, model of good woman, archetype, Basque Country.

\section{Introducción}

Como ya indicó $\mathrm{M}^{\mathrm{a}}$ del Carmen García Herrero, las asociaciones que se localizan en las fuentes medievales respecto al adjetivo "buena", aplicado a las mujeres, distan notablemente de lo que hoy podría entenderse como tal (2007: 275-277). Los primeros estudios realizados en España sobre el modelo ideal de mujer postulado en la

\footnotetext{
${ }^{1}$ Fecha de recepción: 15/11/2019.

Fecha de aceptación: 19/12/2019.

${ }^{2}$ Profesora adjunta, Departamento de Didáctica de las Ciencias Sociales, Universidad del País Vasco, Bilbao, España; $\square$ janire.castrillo@ehu.eus. Este trabajo ha sido financiado por el grupo de investigación IT896-16 Sociedad, Poder y Cultura (ss. XIV-XVIII) del Gobierno Vasco.
} 
tratadística y en la literatura medieval, señalaron con claridad que la castidad era una de las virtudes que más estrechamente se vinculaba a dicho arquetipo (Lacarra 1988; Rábade 1988). Trabajos posteriores indicaron que también la devoción, la caridad, la piedad y el cuidado del prójimo fueron cualidades femeninas importantes (Beceiro 2007). Más recientemente, desde el análisis del discurso de las propias mujeres de la cúspide estamental, se han añadido nuevos elementos a tener en cuenta, como el autocontrol, el comedimiento, la compasión, la justicia, la laboriosidad o el manejo no ostentoso de símbolos del poder (García Herrero 2015).

Ciertamente, a finales de la Edad Media se impuso a las mujeres el cumplimiento de un catálogo de virtudes asociadas a la moral cristiana, aunque no estrictamente religiosas (Muñoz 1989; Toro 2012), para conminarlas a caminar hacia la perfección mariana (Pérez de Tudela, 1993). Algunos pensadores coetáneos, imbricados de misoginia, argumentaron la necesidad de establecer esas pautas de encauzamiento, pues consideraban que las mujeres eran seres débiles, lujuriosos, chismosos y promotores de alborotos, entre otros muchos defectos (Muriel 1991; Martínez 2004; Cabanes 2005; Beteta 2009). Desconfiando de ellas, las convenciones sociales y el Derecho se esforzaron por preservar su honestidad, protegiéndolas de los demás y de sí mismas (Rodríguez 2010). Se las hizo objeto de regulaciones que acotaron su presencia y sus posibilidades de actuar en los espacios públicos, que restringieron su capacidad de participar en acontecimientos comunitarios de diversa índole y que establecieron una separación sexual de espacios de convivencia en las calles y en la iglesia (Casagrande 1992: 112-120).

Por medio de este estudio queremos ahondar en el análisis del modelo de buena mujer vigente a finales de la Edad Media, con un especial interés por aproximarnos a la realidad de las mujeres de extracción social humilde. Para ello, esbozamos en las 
páginas que siguen las representaciones que brindan al respecto las fuentes vascas, con testimonios rescatados de fueros territoriales y ordenanzas municipales de varias villas, de documentos notariales custodiados en archivos municipales -principalmente testamentos- y de juicios librados en la Chancillería, así como de distintos pasajes de las crónicas de la región. Por medio de ellas, trataremos de perfilar con distintos ejemplos algunas de las características del código de actuación ideal erigido por la sociedad bajomedieval para las mujeres, y el tipo de conductas que fueron estimadas en el desarrollo de la identidad femenina.

\section{Castidad, honestidad y buena fama}

Uno de los deberes más importantes de las buenas mujeres era tener una conducta sexual ordenada, manteniéndose alejadas del deseo y la lujuria. Así se infiere del hecho de que la injuria femenina más común en los ordenamientos de un amplio espectro espacial y cronológico fuese "puta". Un vocablo que, como inversión del ideal, apelaba a toda mujer que mantenía relaciones sexuales con más de un hombre. Sirvan como ejemplo las ordenanzas municipales de Lekeitio (1486), que además de "puta", añadían injurias del tipo de "parida o prennada por otro omme cualquier que no sea su marido". Este tipo de descalificaciones se sancionaban duramente con tres semanas en la cárcel, 120 maravedís y el deber de desdecirse en la misa mayor ante toda la comunidad, poniendo así de manifiesto la gravedad que cobraban las afrentas (Enríquez et al. 1992: 392).

Las mujeres tenían que tratar de ser castas en las tres maneras posibles de hacerlo: preservando intacta la virginidad antes de tomar estado, orientando el sexo a la 
procreación de herederos legítimos en el seno del matrimonio o siendo fieles a la memoria del marido una vez muerto éste. Efectivamente, si una joven perdía su condición de virgen antes de casarse, quedaba mancillada y perdía expectativas matrimoniales. No obstante, este requisito parecía trivializarse comedidamente entre las gentes humildes, a juzgar por casos como el de María Ochoa de Iturralde, vecina de Sondika. No en vano, en un pleito de 1512 ésta indicaba haberse casado con cierto varón, tras haber sido estuprada anteriormente por Pedro Ibáñez de Asua y haber obtenido de éste 10.000 maravedís en compensación "a su desfloración”3. Asimismo, el Fuero Nuevo de Vizcaya, de 1526, daba noticia de la existencia de mujeres que "son de edad crecida y pobres y se temen quedar en cabello envejecidas", las cuales inducían a varones a estuprarlas, para poder así mostrarse públicamente con un tocado, símbolo de las mujeres casadas (Zugaza 1976: tít. 12, 4). Lo cual estaría indicando que, para ellas, era preferible la desconsideración social que suponía perder la virginidad fuera del matrimonio, frente a la que se derivaba del hecho de quedarse "solteronas".

La bondad en las mujeres casadas pasaba necesariamente por no dar pie a sospechas acerca de la legitimidad de los descendientes. En efecto, mientras los hombres fueron libres para relacionarse con prostitutas o mancebas, para las mujeres la fidelidad fue una premisa insoslayable. En Las Bienandanzas e fortunas, crónica redactada por el vizcaíno Lope García de Salazar en el siglo XV, se contaba como Álvaro Díaz de Oca, al vanagloriarse de la valentía mostrada por uno de sus hijos en cierta batalla del siglo XI, exclamó que "agora sé yo que mi muger era buena, que aquel su fijo de mi rodilla salió” (Villacorta 2015: 536), asociando la certeza de su paternidad a la bondad de su esposa. El mismo cronista exponía el ejemplo contrario, dando cuenta de cómo Ladrón de Leiva había asesinado a su esposa por serle infiel y "porque se dezia

\footnotetext{
${ }^{3}$ Archivo de la Real Chancillería de Valladolid, Reales Ejecutorias, caja 271/20.
} 
ser mala de su cuerpo" (Villacorta 2015: 713).

El ideal de castidad afectó también a las viudas, ya que se consideró preferible que no contrajesen segundas nupcias. Muchos hombres introdujeron en sus testamentos peticiones expresas para que sus esposas permaneciesen en estado viudal tras su muerte y prescribieron la pérdida de ciertos privilegios para el supuesto de que volviesen a casarse. Se trataba de un modo de conservar el honor familiar, así como de una vía para asegurar que los hijos e hijas del matrimonio no tendrían que competir por la herencia con los posibles descendientes de una segunda unión de su madre viuda. Por ejemplo, Ochoa López de Echevarría, vecino de Elgoibar, condicionó en 1502 el derecho de su esposa a ser usufructuaria de su casería de Echevarría al requisito de que permaneciese en viudedad: "si ella quisiere estar en mi honestidad, en uno con los mis cabezaleros entienda y que sea duenna de la caseria de Echebarria. E si ella quisiere salir, que le den su dote"4.

La estricta moral de la época impulsó toda una serie de medidas preventivas para proteger la honra y bondad femeninas. Entre otras cosas, promovió una división del espacio público por sexos, lo cual se materializó en forma de lugares de asiento diferenciados para hombres y mujeres en la iglesia, en tiempos distintos para realizar la ofrenda e ir en procesión, o en espacios de ocio separados. Se prescribieron dictámenes para una clara demarcación de este orden, previendo penas en metálico para quienes osaran romperlo. Así ocurrió en Bilbao, cuando en 1509 las autoridades, con ánimo de evitar todo tipo de contacto clandestino, ordenaron que las ventanas a ras de calle de todas las casas de la villa se cerrasen con redes, pues en el salir y entrar a través de ellas habían ocurrido muchos "abusos y vicios" (Enríquez et al. 1995a: 16). Con similares objetivos, el regimiento estableció en 1512 “que ningunas nin algunas mugeres nin

\footnotetext{
${ }^{4}$ Archivo General de Protocolos de Guipúzcoa, caja 2/0798.
} 
beatas sean osadas de se sentar en las yglesias en ningunos bancos que estan puestos para se sentar los onbres", sino que "sean sentadas avaxo, sobre sus fuesas, en tierra o sobre sus tajos, so pena de çient maravedis" (Enríquez et al. 1996: 183).

Las posibilidades de relacionarse entre personas de ambos sexos quedaron así restringidas. Pero, en el caso de las buenas mujeres, las limitaciones se extendieron aún más, ya que, en aras de preservar su buena fama, sus salidas fuera de la casa quedaron circunscritas a la vecindad próxima, la iglesia o a espacios feminizados como las fuentes, los lavaderos o los hornos. Evitar poner en entredicho su honestidad era una responsabilidad que empezaba por ellas mismas que, si querían ser consideradas buenas, tenían que evitar frecuentar lugares despoblados, alejarse de las inmediaciones del hogar o salir durante la noche.

En un pleito librado en 1519 entre la villa de Lekeitio y la anteiglesia de Ispaster por los derechos de explotación sobre el monte Otoio, varias deponentes indicaban desconocer las partes más alejadas del mismo, dejando patente que no era usual que las mujeres se desplazaran hasta lugares tan remotos. Entre ellas, María de Arana afirmaba que "esta que depone, commo es muger, nunca ha llegado en ellas e non sabe por donde se dividen ni se parten" (Enríquez et al. 1993a: 53). Pese a ello, hay evidencias de muchas mujeres que se desplazaron a lugares alejados, bien para realizar trabajos de jornaleo, o bien para acudir a mercados de referencia a vender en ellos el excedente doméstico. Pero, en estos casos, las fuentes señalan que los viajes solían realizarse en grupo. Lo demuestra el propio pleito de Otoio, cuando hace referencia a numerosas mozas de Lekeitio, que acudían a los montes a pastar puercos o recoger leña (Enríquez et al. 1993a: 91). También lo expone la documentación bilbaína, que alude a las "plumeras", mujeres que venían en cuadrilla de las anteiglesias cercanas y se adentraban 
en la villa para comprar lienzos con los que elaboraban cojines, colchas y otros productos (Enríquez et al. 1996: 141-143).

\section{Asistencia parental y solidaridad vecinal}

Otro requisito insoslayable para ser considerada una buena mujer era cumplir con una serie de solidaridades y reciprocidades hacia la parentela y la vecindad. Era de especial importancia en este punto el cometido de honrar la memoria de los parientes difuntos con ofrendas funerarias. Se trataba de un campo de acción exclusivamente femenino que se entendía, junto a las misas, como fundamental para salvar el alma del fallecido o fallecida. En muchos testamentos se reclamaba a hijas, esposas, madres, tías y otras familiares o criadas para que desempeñasen esta labor, consistente usualmente en colocar obladas de pan y luminaria sobre las sepulturas. Por ejemplo, Martín Fernández de Paternina, bachiller de Salvatierra, solicitó en 1467 a María Martínez, su hija, que durante los dos años posteriores a su muerte realizase diariamente entrega de una oblada de media blanca en su tumba. Detallaba que aquella debía gastarse media blanca en cada oblada y "quanto se pudiere gastar" en candelas, proporcionándole a cambio 500 maravedís por su trabajo (Lema 2007: 23).

Dentro del ámbito de la asistencia parental, otra función primordial de las mujeres era el acompañamiento de sus allegados en momentos importantes como nacimientos, bodas o funerales. La obligación de acudir a estos eventos competía a toda la familia, si bien en las mujeres recaía, en particular, estar al lado de otras mujeres. Acompañaban a las novias que iban a contraer matrimonio, a las novicias que profesaban, a quienes acababan de dar a luz o a las viudas recientes en el velatorio y el funeral. Múltiples 
ordenanzas bilbaínas de entre 1479 y 1520 reflejan estas costumbres, dando cuenta de los séquitos femeninos que seguían a las protagonistas de estas celebraciones, como cuando en 1499 se estableció que en las bodas la novia "que entre en la iglesia el primer dia puede llebar a veinte mugeres" (Enríquez et al. 1996: 144).

Era un gesto igualmente obligado acudir a visitar a las mujeres que habían traído recientemente un hijo o hija al mundo. Familiares, amigas y vecinas se acercaban a sus casas portando regalos, como se recoge en varios capitulados concejiles, como el de Bilbao (Enríquez et al. 1996: 73, 94, 106) o el de Orduña (Enríquez et al. 1994: 304). También en el Fuero Nuevo de Bizkaia (1526) señalaba que: "acostumbran las mujeres ir a visitar otras mujeres cuando estan paridas, acompañadas y con presentes". La disposición buscaba la erradicación de esta tradición, que "resulta daño en la tierra", y sancionaba con 600 maravedís a quienes persistiesen en mantenerla (Zugaza 1976: tít. 35,7). La prohibición se enmarcaba en toda una serie de medidas dirigidas a disminuir los gastos que se hacían en este tipo de eventos, buscando la ostentación y la pompa, y la costumbre de usar el parentesco amplio para escenificar el poderío familiar o clientelar en la comunidad.

Entre las autoridades que trataron de minimizar estos usos, figura el concejo de Gernika, que a través de una ordenanza de finales del siglo XV, señaló que "por evitar algunos males, (...) vanagloria e daño e perjuicio de los vecinos desta villa, mandamos que hecho el novenario (...), que ningunas mugeres vayan con la biuda ny con la parienta de tal difunto a su casa desde la iglesia en honra”, penándolo con 70 maravedís (Arízaga et al. 1986: 229). Es de suponer que la costumbre de realizar estas visitas de cortesía quedaría progresivamente ceñida a la parentela inmediata, aunque la reiteración de las medidas prohibicionistas certifica la vigencia de estas prácticas a finales de la época medieval. 
El deber de acompañar y asistir a la familia se extendía también al vecindario, como bien ilustran las ordenanzas de las vecindades de Vitoria (1483). Éstas obligaban al conjunto de vecinos y vecinas a ir a la iglesia en busca de la comunión para quienes se hallaban convalecientes o a velar a los muertos de su misma vecindad, e imponían pequeñas penas pecuniarias a quienes no lo hacían (Jiménez 1969: tít. 4-5). En este sentido, las fuentes ofrecen numerosos ejemplos de prácticas femeninas de solidaridad vecinal. Una ordenanza bilbaína de 1496 daba noticia de cómo las horneras contribuían al bienestar del vecindario, pues por las noches "repartian su braza e fuego a los vezinos del barrio e de la dicha villa" (Enríquez et al. 1996: 115-116). Igualmente, en cierto pleito de 1535 María Martínez de París, de Andoain, contaba que muchas veces solía dar "panes enprestados" a su vecina, Catalina, vista la miseria en la que aquella vivía, por ser madre soltera de tres hijos ${ }^{5}$. Asimismo, puede citarse la obligación que existía en multitud de localidades para colaborar en la extinción de incendios. Un deber, que se adjudicaba a las mujeres de manera específica, quizá porque ellas eran quienes permanecían en el seno del municipio, cerca de sus casas, buena parte de la jornada. Pueden citarse, entre otras, las ordenanzas municipales de Tolosa, de 1532, que indicaban "que quando prendiere fuego en alguna casa de la villa, las mugeres acudan con erradas", bajo pena de un real castellano (Lema 2007: 398).

\section{Devoción y caridad}

El modelo de buena mujer erigido en las postrimerías del bajomedievo proponía como otro requisito fundamental el ser devota y piadosa. Los testamentos femeninos, al

\footnotetext{
${ }^{5}$ Archivo de la Real Chancillería de Valladolid, Pleitos Civiles, Escribanía Masas, Fenecidos, caja 611/2.
} 
igual que los masculinos, retratan el carácter eminentemente cristiano de las gentes medievales y el arraigo que en ellas tenían las creencias difundidas por la Iglesia. Sancha de Labiero, vecina de Lekeitio, daba su última voluntad en 1422 señalando "que por otra cosa el omme non puede seer saluo, si non por la nuestra Santa Fe Catolica”. Decía estar temerosa por la proximidad del Juicio Final y ofrecer "la mi anima a Nuestro Sennor Ihesu Christo, donde la yo oue e cuya es, que dio la suya por la mia, e pidole por merçed que la quiera recibir por mano de los santos angeles". Apelaba para ello a la mediación de "la Uirgen Santa Maria, en quien fue siempre e es toda mi esperanza de Dios en ayuso, que ella sea rogadora e rasonadora por mi” (Enríquez et al. 1993c: 68).

Las fuentes ofrecen una amplia variedad de ejemplos en los que las mujeres aparecen acudiendo asiduamente a la iglesia. Sobre la importancia de la devoción en las mujeres, resulta ilustrativo un expediente relativo a María San Juan de Garonda, partera de Mungia, que esbozaba un retrato de sí misma acorde a la imagen de bondad que tenía interiorizada, al defenderse de una acusación de brujería en 1508. Además de afirmar "gozar de buena fama, vida y opinion", mencionaba "que era buena cristiana" y, para afianzarlo, contaba que frecuentemente "acudia a la iglesia a oir misa, visperas, sermones y a los demas divinos ofiçios”. Decía, además, que había ido en peregrinación a Santiago de Compostela y a Nuestra Señora de Guadalupe, en Hondarribia. También recalcaba su espíritu caritativo, pues "acudia a los ospitales de la dicha villa y haçia limosna a los pobres, y que hacia su ofrenda a los clerigos" (Aranda 2010: 420-422).

En efecto, la caridad era otra de las virtudes que se presuponía a las buenas mujeres, que debían tener una actitud misericordiosa con el prójimo. Así, en diversas ordenanzas municipales bilbaínas de 1487 se citaba a algunas mujeres que recorrían las calles con tazas para recolectar limosnas para las iglesias de la villa (Enríquez et al. 
1996: 47). También se perfilaban los hornos, espacios feminizados, como lugares recurrentes para los pobres y religiosos que solicitaban limosnas: "ninguna hornera no sea hosada de dexarle entrar a ningund frayle ni freira nin a prove, (...) e asimismo que ninguna vezina sea hosada de dar nin de ningunas limosnas a los sobredichos, so pena de çient maravedis" (Enríquez et al. 1996: 90).

Las acciones caritativas dirigidas a ayudar a personas pobres a subsistir o a conseguir una dote, a financiar o reparar hospitales y conventos, a acrecentar la fábrica de las iglesias o el lujo de los templos, estaban presentes en la mayor parte de los testamentos de hombres y mujeres. No en vano, estas donaciones se presentaban como uno de los recursos para salir bien parado en el Juicio Final. El libro de cuentas de la iglesia parroquial de Santa María de la villa de Lekeitio, por ejemplo, registraba en 1499 múltiples donaciones de este tipo: Marina de Hormaegui había dado 144 maravedís por el testamento de su hermana Catalina, por el de Ochanda de Arostegui se dieron 80, por el de María Martínez de la Plaza 135, Catalina de Amlax pagó 369 por el de su marido, etc. (Enríquez, Javier et al. 1993b: 146). Las mujeres de los sectores sociales mejor posicionados realizaron donaciones de una mayor entidad, en consonancia con sus posibilidades económicas. En 1469, por ejemplo, doña Catalina Martínez de Arbolancha, "muger que fue de Galaz de Legiçamon", miembro de una de las familias más importantes de la villa de Bilbao, fundó dos perpetúales a favor de los pobres del hospital de los Santos Juanes, que comprendían 500 maravedís anuales en leña (Enríquez et al. 1999: 394-397).

Las mujeres que más se aproximaron a los ideales cristianos de piedad, caridad y asistencia, y por lo tanto a la noción de bondad de su tiempo, fueron las religiosas profesionales. Las beatas y seroras, desde su posición cercana al común, adquirieron un gran valor social y fueron reclamadas por los legos para actuar como mediadoras con 
Dios, para rezar por el alma de los difuntos o para hacerse cargo de regentar hospitales. Una disposición municipal de Bilbao prohibía en 1505 a los vecinos y vecinas de la villa entrar en las casas de estas religiosas con 3.000 maravedís. Y establecía que, si alguien deseaba hablar con ellas, debía llamarlas y hacerlas bajar a la calle, dejando en evidencia lo comunes que debían ser estas visitas: "que ningund lego sea osado de entrar nin subir en casa alguna nin de ninguna beata que sea en la dicha villa e sus rebales. (...) Sy alguno quisiere hablar con alguna dellas, que en tal caso las llame abaxo e publicamente, en la calle, able con ellas” (Enríquez et al. 1996: 161-162).

Asimismo, los monasterios, que fueron espacios abiertos generalmente a un público más elitista, constituyeron centros de acogida y socialización femenina. Muestra de ello es el hecho de que numerosas legas se retiraran a algún cenobio durante ciertos periodos de sus vidas. Buena parte lo hicieron durante su vejez, para terminar sus días dedicadas a Dios y a la oración, como María Díaz de Haro, señora de Bizkaia, de quien Lope García de Salazar indicaba que: "seyendo esta doña Maria vieja de edad, dio el Señorio de Viscaya e todos los otros heredamientos a don Juan, su fijo, que era ya ome de XXII años o mas, e metiose monja en serviçio de Dios” (Villacorta 2015: 697).

\section{Humildad, recato, formalidad y cuidado de las apariencias}

En las fuentes medievales es fácil detectar a la templanza, la obediencia y la moderación como cualidades básicas de las buenas mujeres. En efecto, el alboroto femenino generaba un gran rechazo social, y el descrédito atribuido a aquellas que osaban romper los límites del decoro se verifica con nitidez en la figura de las "profazadas". Unas mujeres que, inmersas en el trasiego de la calle, promovían 
escándalos vecinales y actuaban con soberbia y sin reputación moral. Su presencia "no controlada" en los espacios públicos se penó con rigor. El Fuero Viejo de Bizkaia, de 1452, situó el comportamiento de estas mujeres entre los delitos que podían ser perseguidos de oficio (Hidalgo de Cisneros et al. 1986: tít. 37). En 1526 el Fuero Nuevo de Bizkaia volvió a hacerlo, definiéndolas como "mugeres que son conocidas por desvergonzadas y revolbedoras de vecindades, y ponen coplas y cantares a manera de libelo" (Zugaza 1976: tít. 8,1)

En una sentencia dada a raíz de un episodio de violencia banderiza ocurrido en Markina en 1470 aparecía un grupo de mujeres "porasadas e desporasadas". Parecían estar vinculadas al mundo marginal de los sicarios que servían a los parientes mayores y fueron desterradas de la mencionada villa vizcaína por haber cometido faltas contra la moral sexual, haber causado "ruidos" y haber injuriado a mujeres honestas (Munita \& Díaz de Durana 2009: 250-251). También aparecía este tipo de mujeres "profazadas” en una queja recibida en 1509 por el concejo de Bilbao, a causa del deshonesto modus vivendi y de los altercados que con frecuencia promovía un grupo de personas que residía en cierto hospital, carente de administrador o responsable alguno. Entre ese grupo de personas, se citaba de manera expresa a "la muger de Juan Peres de Mondragon e Teresa de Vilela", ambas "muy porasadas, que estan todavia renniendo e soberbyos" (Enríquez et al. 1995b: 41-42). Sólo a ellas se les aplicaba el mencionado calificativo, quizá porque se trataba de un delito exclusivamente femenino, y quizá también, porque la sociedad de entonces atribuía mayor gravedad a la promoción de altercados por parte de las mujeres.

Las medidas que buscaban el desarrollo de un comportamiento recatado, se extendieron a otros ámbitos más cotidianos. Por ejemplo, las mujeres vieron limitada su libertad para acudir a la iglesia, pues al parecer, muchas utilizaban el deber de cumplir 
con las obligaciones litúrgicas como un pretexto para huir de la rutina doméstica y reunirse con amigas. El férreo marco que les fue impuesto queda patente en las ordenanzas concejiles de Gernika, de la segunda mitad del siglo XV, que las responsabilizaban del "regozijo e bullicio" que surgía en el templo a la hora de la misa, indicando que hacían ruido llamándose unas a otras y moviéndose de un lado a otro:

Mandamos que, por quanto asi en tienpos de honras como en otros tienpos, muchas mugeres desta villa e de fuera que a ella vienen se suelen llebantar de sus lugares llamando a las que de nuevo vienen e se llebantan todas, donde creçe mucho regozijo de manera que muchas vezes turba a los sacerdotes que dizen las mysas e a los que las oyen, mandamos que (...) ninguno se llebante so pena de sesenta maravedis, (...) salvo esten quietas todas haziendo oracion syn bullicio e ruydo alguno. (Arízaga et al. 1986: 230)

Esas mismas ordenanzas, vetaban la asistencia de mujeres a las misas diarias de vísperas, acotando sus posibilidades de acudir a ellas a las que se celebraban en día de sábado, domingo y de misa solemne. Adicionalmente, les ordenaban permanecer en casa hasta que sonaran las campanas llamando a los oficios, para evitar los corrillos que formaban a las puertas de la iglesia mientras esperaban que diera comienzo la misa. Se justificaba esta restricción atribuyéndoles el papel de murmuradoras y parlanchinas, pues "en son de servir a Dios, ban a las iglesias desta villa a misa e a visperas ante que tangan la campana, e estan sobre sus fuesas dellas en deservicio de Dios deziendo endechas e otras parlando; e a causa desto biene daño a sus faziendas" (Arízaga et al. 1986: 121).

Precisamente, otra ordenanza guerniquesa insistía en la prohibición de "dezir endechas y de fazer otras desonestidades en la casa del difunto", bajo sanción de 120 maravedís (Arízaga et al. 1986: 121). En efecto, todo indica que las mujeres tenían por costumbre cantar endechas, o versos improvisados, especialmente con ocasión del 
funeral de algún pariente cercano y en honor al mismo. Esta tradición femenina fue tenazmente vetada a finales del siglo XV, hasta su completa erradicación en el XVI. No en vano, se trataba de un uso que hacía salir a las mujeres a la palestra pública y las dotaba de protagonismo social, alejándolas de las cualidades de recato y vergüenza que de ellas se esperaban.

De modo paralelo, se les negó la posibilidad de andar por las calles en cuadrilla anunciando eventos, como ocurrió en Bilbao con las "misas nuevas" de los curas debutantes. En 1508 el concejo prohibió que realizasen dicha labor, bajo una elevada pena de 10.000 maravedís, pues el hecho de que las mujeres se inmiscuyeran libremente en las calles para ir por ellas dando gritos a modo de pregón "es cosa muy deshonesta" y “paresçe a los estrangeros ser cosa mui desabominable” (Enríquez et al. 1996: 170-171). Por ello, se ordenó que, en adelante, un grupo de doce hombres se encargase de realizar estos anuncios. Pero la ordenanza se topó con una fuerte resistencia, también por parte de la clerecía local, de manera que, al año siguiente, las autoridades permitieron que ciertas mujeres salieran a invitar a la comunidad a la "misa nueva" de Martín Abad de Arza, "segund e commo en los tienpos pasados solian andar" (Enríquez et al. 1995a: 3339). La costumbre fue verdaderamente difícil de desterrar y en 1512 volvió a aceptarse la presencia de doce hombres y hasta veinte mujeres anunciando estas misas:

Quier que algund clerigo vesino e fijo de vesino e morador en ella ubiere de desir e cantar misa nueba en las iglesias desta dicha villa, puedan andar e anden a conbidar para el ofresçimiento de la misa nueba de tal misacanto fasta doze onbres e veinte mujeres. (Enríquez et al. 1996: 170-171)

La mesura y el recato fueron cualidades estimadas en las buenas mujeres y el deber de mantener la compostura se hizo extensivo también al ámbito de la representación pública del estatus personal o "más valer". Guardar las apariencias fue 
un asunto importante en las sociedades medievales, orientadas al ideal nobiliario y en las cuales el simbolismo del honor irradiaba todos los espacios de la vida comunitaria. Las buenas mujeres tuvieron ámbitos y símbolos propios para poner en liza su prestigio, y las autoridades se esforzaron porque hiciesen un desarrollo ordenado de esta responsabilidad. Uno de los elementos a través de los cuales las mujeres escenificaron su valor social fue a través de la vestimenta. Las ordenanzas municipales de Deba, de 1434, reflejaban que el tocado era usado para tal fin, cuando señalaban que éste no podía estar formado por "mas de treynta e vna baras de lienço delgado y mas seis baras de lienço gordo" y que no podían ponerse "en las dichas sus tocas oro nin seda alguna, so pena de dos doblas de oro" (Herrero \& Barrena 2005: 100).

También la sepultura familiar y las ofrendas funerarias fueron recursos utilizados para exaltar el estatus social de las oferentes. La competencia por decorarlas lujosamente fue fuente de altercados, lo cual dio lugar a que estos usos se regulasen en más de una villa. En 1493 el concejo de Bilbao determinó que las telas decorativas que las mujeres usaban para adornar las tablas sobre las que transportaban sus obladas, no pudiesen ser más que un pequeño "cubrichel, de manera que non colgare de fuera mas de la tabla, e que no tenga dobladura". Y estableció, igualmente, el deber de llevar las telas de vuelta a casa tan pronto como terminasen las honras (Enríquez et al. 1996: 110111).

Las mujeres que carecían de una sepultura familiar sobre la cual escuchar las misas, buscaron ensalzar su valía pagando por que alguien transportase para ellas "tajos" o sillas, algunos de gran tamaño y calidad, hasta la iglesia. Varias ordenanzas bilbaínas de 1479 y 1493 determinaron que los "tajos" no podían superar el codo de altura, que debían ser para una sola mujer y que debían llevarse de vuelta a las casas tras cada misa (Enríquez et al. 1996: 103-104). Sin embargo, todavía en 1499 se hacía 
hincapié en que "ninguno tenga tajo en la iglesia, saluo que lo faga llevar, que sean en longor media bara e non mas" (Enríquez et al. 1996: 143); insistiendo en ello también en 1514 (Enríquez et al. 1996: 249).

\section{Conclusiones}

El modelo de perfección ético-moral por el que quedó mediatizada la socialización femenina a finales de la Edad Media, reunía una serie de cualidades que afectaban a distintos ámbitos. Los requisitos a cumplir pasaban, en primer lugar, por mantener un comportamiento sexual ordenado en todos los estadios vitales. De la castidad derivaban la "buena fama" y honestidad de las mujeres, que éstas irradiaban a todo el grupo de parentesco, como responsables de asegurar la pureza y legitimidad de la descendencia. Esta cuestión se trataba de modo más laxo entre las clases humildes y se abrían algunas fisuras al modelo ideal, como por ejemplo, la posibilidad de revertir el efecto negativo de haber perdido la virginidad antes del matrimonio, llegando a casarse y viviendo a la postre como buenas mujeres.

En cualquier caso, una mujer virtuosa debía esforzarse por tomar las medidas necesarias para no entablar contacto alguno con hombres que no fuesen de su parentela inmediata, respetando la estricta separación del espacio público en función del sexo impuesta por las autoridades locales en aras de la precaución. Además, debía optar por permanecer el mayor tiempo posible en el espacio doméstico, alejada de peligros y tentaciones. Y abandonar aquel, casi únicamente, para desarrollar las funciones asociadas a sus esferas de acción socio-laboral: acudir a misa, relacionarse en la vecindad próxima e ir al horno, al mercado, al lavadero... 
Ser una buena mujer suponía también ser una buena pariente y asumir el deber de honrar la memoria de los familiares difuntos y realizar las ofrendas funerarias requeridas para la salvación del alma de aquellas personas. Implicaba, igualmente, el deber de acompañar a las allegadas en momentos importantes como su boda, tras dar a luz, al enviudar... Además de tener que cuidar los estrechos vínculos familiares, era importante que las buenas mujeres diesen muestras de solidaridad y asistencia en la vecindad, contribuyendo al bienestar de aquellos vecinos o vecinas que se hallaban en situaciones de necesidad, así como colaborando activamente en ciertos menesteres, como la extinción de incendios.

A finales de la Edad Media, ninguna mujer era buena si no era devota y caritativa. Las religiosas profesionales, especialmente las beatas y seroras, cumplieron fielmente este prototipo. Pero también las legas acudieron al templo a orar con asiduidad, y los espacios femeninos, los hornos por ejemplo, fueron lugares preferentes donde ir a pedir limosnas. No obstante, ir a misa, al ser una de las pocas excusas que las mujeres tuvieron para salir de la rutina doméstica, fue utilizada para socializarse y reunirse con amigas y vecinas. Un hábito que fue limitado por las autoridades locales, por considerar que rompía con otra de las cualidades que debían tener las mujeres virtuosas: el recato.

Ciertamente, el alboroto tenía una pésima consideración en las mujeres y fue penado con rigor. Además, los legisladores trataron de erradicar algunos usos que hacían salir a las mujeres a la palestra pública, con ánimo de que su rol social se enmarcase en un modelo actitudinal basado en la humildad, la discreción y el silencio. Entre las prohibiciones más destacables, se sitúa la relativa al canto de endechas, versos improvisados en honor a los allegados en su funeral. Una tradición que desapareció durante el siglo XVI, debido a la tenacidad con la que fue perseguida. 
Finalmente, la acción de las autoridades se orientó también a hacer engarzar la importancia que cobraba en las comunidades medievales el cuidado de las apariencias y la representación social del estatus, con las cualidades de moderación y comedimiento asociadas al arquetipo de buena mujer. Y así, trataron de ordenar y acotar las vías y espacios comunitarios que utilizaban las mujeres para exaltar su valía o "más valer", por ejemplo, limitando la suntuosidad en el adorno de las ofrendas funerarias que llevaban a las sepulturas en honor a sus parientes difuntos.

\section{Referencias documentales de fuentes publicadas}

Enríquez, Javier; Hidalgo de Cisneros, Concepción; Lorente, Araceli y Martínez, Adela. 1992. Colección documental del Archivo Municipal de Lequeitio (1474-1495), t. II. San Sebastián: Eusko Ikaskuntza.

- 1993a. Colección documental del Archivo Municipal de la villa de Lequeitio. Pleito sobre el monte Otoyo. San Sebastián: Eusko Ikaskuntza.

. 1993b. Libro de visitas del corregidor (1508-1521) y libro de fábrica de Santa María (1498-1517) de la villa de Lequeitio. San Sebastián: Eusko Ikaskuntza.

1993c. Colección documental de los monasterios de Santo Domingo de Lequeitio (1289-1520) y Santa Ana de Elorrio (1480-1520). San Sebastián: Eusko Ikaskuntza.

. 1994. Colección documental del Archivo Municipal de Orduña (12711510), t. I. San Sebastián: Eusko Ikaskuntza.

1995a. Libro de acuerdos y decretos municipales de la villa de Bilbao (1509 y 1515). San Sebastián: Eusko Ikaskuntza.

. 1995b. Libro de autos judiciales de la alcaldía (1419-1499) y libro de acuerdos y decretos municipales (1463) de la villa de Bilbao. San Sebastián: Eusko Ikaskuntza.

1996. Ordenanzas municipales de Bilbao (1477-1520). San Sebastián: Eusko Ikaskuntza.

1999. Colección documental del Archivo Histórico de Bilbao (13001473). San Sebastián: Eusko Ikaskuntza. 
Herrero, Victoriano José y Barrena, Elena. 2005. Archivo Municipal de Deba (11811520), t. I. San Sebastián: Eusko Ikaskuntza.

Hidalgo de Cisneros, Concepción; Largacha, Elena; Lorente, Araceli y Martínez, Adela. 1986. Fuentes jurídicas del Señorío de Vizcaya. Cuadernos Legales, Capítulos de la Hermandad y Fuero Viejo (1342-1506). San Sebastián: Eusko Ikaskuntza.

Jiménez, Joaquín. 1969. "Agrupaciones vecinales alavesas (Esquema de su administración y gobierno)". Boletín de la Institución Sancho el Sabio, 13: 191205.

Lema, José Ángel. 2007. Colección documental del Archivo Municipal de Bergara. Fondo Iturbe-Eulate (1401-1520), t. III. San Sebastián: Eusko Ikaskuntza.

Munita, José Antonio y Díaz de Durana, José Ramón. 2009. "El archivo familiar de los Barroeta de Marquina: aportaciones para la reconstrucción de un conflicto banderizo en los confines de Vizcaya". Castilla y el mundo feudal. Homenaje al profesor Julio Valdeón. Coord. Ma Isabel del Val y Pascual Martínez. Valladolid: Universidad. 239-252.

Villacorta, $\mathrm{M}^{\mathrm{a}}$ Consuelo. 2015. Libro de las buenas andanças e fortunas que fizo Lope García de Salazar. Bilbao: Universidad del País Vasco.

Zugaza, Leopoldo. 1976. Fuero Nuevo de Vizcaya. Bilbao: Gráficas Bilbao.

\section{Referencias bibliográficas}

Aranda, Eudaldo. 2010. "La quema de brujas de 1507. Notas en torno a un enigma histórico". Huarte de San Juan. Geografía e Historia, 17: 411-422.

Arízaga, Beatriz; Ríos, Ma Luisa y del Val, Mª Isabel. 1986. "La villa de Guernica en la Baja Edad Media a través de sus ordenanzas". Cuadernos de Sección. Historia y Geografía, 8: 167-234.

Beceiro, Isabel. 2007. "Modelos de conducta y programas educativos para la aristocracia femenina (siglos XII-XV)". Libros, lectores y bibliotecas en la España medieval. Murcia: Nausíca. 287-319.

Beteta, Yolanda. 2009. "Representaciones de la sexualidad femenina en la literatura medieval y su influencia en la consideración de las mujeres". Arenal, 16.2: 213233.

Cabanes, Pilar. 2005. "El deseo femenino a la luz de algunas composiciones literarias medievales". Lemir, 4.1-10.

Casagrande, Carla. 1992. "La mujer custodiada". Historia de las mujeres, t. II. Eds. Georges Duby y Michelle Perrot. Madrid: Taurus. 93-131. 
García Herrero, M ${ }^{\mathrm{a}}$ Carmen. 2007. "Urbe palpitante: espacios "sexuados" y vida cotidiana en Zaragoza a finales de la Edad Media". La convivencia en las ciudades medievales. Eds. Beatriz Arízaga y Jesús Solórzano. Logroño: IER. 263290.

2015. "La dama modélica del Cuatrocientos en la correspondencia de María de Castilla, reina de Aragón (1416-1458)". Cuadernos del CEMyR, 23: 2748.

Lacarra, Ma Eukene. 1988. "La mujer ejemplar en tres textos épicos castellanos". Cuadernos de Investigación Filológica, 14: 5-20.

Martínez-Burgos, Palma. 2004. "Lo diabólico y lo femenino en el pensamiento erasmista. Apuntes para una iconografía de género". El Diablo en la Edad Moderna. Eds. María Tausiet y James S. Amelang. Madrid: Marcial Pons. 211231.

Muñoz, Ángela. 1989. "Notas para la definición de un modelo sociorreligioso femenino: Isabel I de Castilla". Las mujeres en el cristianismo medieval. Imágenes teóricas y cauces de actuación religiosa. Coord. Ángela Muñoz. Madrid: Al-Mudayna. 415-434.

Muriel, $\mathrm{M}^{\mathrm{a}}$ Cruz. 1991. Antifeminismo y subestimación de la mujer en la literatura medieval castellana. Cáceres: BPR.

Pérez de Tudela, $M^{\mathrm{a}}$ Isabel. 1993. "El espejo mariano de la feminidad en la Edad Media española”. Anuario filosófico, 26.3: 621-634.

Rábade, M ${ }^{a}$ Pilar. 1988. "El arquetipo femenino en los debates intelectuales del siglo XV castellano”. En la España Medieval, 11: 261-301.

Rodríguez, Victoria. 2010. "Mujeres corrompidas y varones deshonrados. La regulación de los delitos sexuales en la legislación de Alfonso X". Experiencias jurídicas e identidades femeninas. Eds. Rosalía Rodríguez y $\mathrm{M}^{\mathrm{a}}$ José Bravo. Madrid: Dykinson. 531-560.

Toro, Ma Isabel. 2012. "La Biblia y las mujeres en la literatura didáctico-moral española”. La Biblia y las mujeres. Medioevo II (siglos II-XV). Entre recepción e interpretación. Eds. Kari E. Borresen y Adriana Valerio. Madrid: Verbo Divino. 61-74. 